
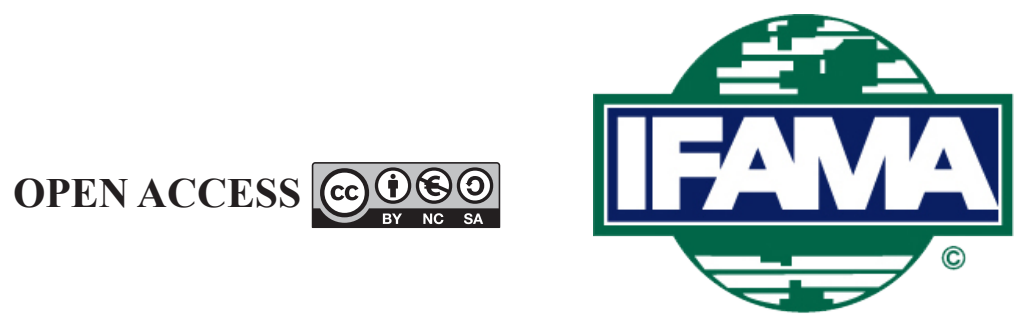

International Food and Agribusiness Management Review

Volume 24, Issue 1, 2021; DOI: 10.22434/IFAMR2019.0206

Received: 5 December 2019 / Accepted: 15 September 2020

\title{
Dynamic price relationships and price discovery among cheese markets \\ RESEARCH ARTICLE
}

\author{
Hernan A. Tejeda ${ }^{\circledR a}$ and Man-Keun Kim ${ }^{b}$ \\ ${ }^{a}$ Assistant Professor, Department of Agricultural Economics and Rural Sociology, University \\ of Idaho, Twin Falls R\&E Center, P.O. Box 1827, Twin Falls, ID 83303, USA \\ ${ }^{b}$ Associate Professor, Applied Economics Department, Utah State University, \\ AGRS 421, 4800 Old Main Hill, Logan, UT 84322-4800, USA
}

\begin{abstract}
The United States (U.S.) cheese sector has been steadily growing throughout the years. Since 1980, U.S. consumers have doubled their annual consumption of cheese, currently at about 37.9 lbs. per capita in 2018 excluding cottage cheese. Cheese varieties are generally classified as American type (Cheddar, Monterey and others), Italian type (Mozzarella and others), and Other type (Swiss, Muenster and others) since they serve different markets. American cheese is consumed regularly in hamburgers, sandwiches and in similar settings. Italian cheese is typically consumed in pizzas, pasta and Italian cuisine. Despite the burgeoning growth in cheese demand, there has been no study addressing the dynamic price relationship among different varieties of cheese. This study investigates the price discovery process among cheese varieties: Cheddar, Mozzarella, Swiss, Muenster, and Monterey by using a vector error correction model and standard innovation accounting. Results indicate relative price interaction among different varieties of cheese, providing empirical evidence of some decouplment or separation among American (Cheddar and Monterey), Italian (Mozzarella), and Other type (Swiss). An exemption is Muenster which despite being classified as Other type of cheese responds to American's Cheddar.
\end{abstract}

Keywords: cheese industry, cheese markets, dynamic cheese price relationship, price discovery process, price decouplment

JEL code: Q11, Q13, C32

${ }^{\oplus}$ Corresponding author: htejeda@uidaho.edu 


\section{Introduction}

The cheese sector is generally partitioned according to distinct varieties grouped under three different types ${ }^{1}$ : (1) American, which includes Cheddar, Colby, Monterey and Jack; (2) Italian, which includes Mozzarella, Parmesan, Provolone, Ricotta, and Romano; (3) Other, which includes Swiss, Cream and Neufchatel, Hispanic, Brick and Muenster ${ }^{2}$. For American cheese, consumption of Cheddar is regularly utilized in fast-food settings (e.g. hamburgers, sandwiches, wraps, etc.); where for Italian cheese, Mozzarella is frequently applied in pizzas, pasta or other Italian, southern European cuisine. These two varieties of cheese - of different types - dominate the consumption volume among cheese markets, experiencing increased growth through the years. Less consumed varieties of cheese such as Monterrey Jack, from the American type, have also seen their consumption increase from past years. However, consumption of Swiss as well as Brick and Muenster from the Other type, have remained steady. Figure 1 shows varieties of cheese from different types, annually consumed per capita in the United States (U.S.) from 1990 to 2016. Data from ERS-USDA (2017) notes that from 1995 through 2016, U.S. per capita consumption of Cheddar and Mozzarella increased by 15 and $48 \%$, respectively. This translates to an approximate annual per capita consumption in 2016 of $10.4 \mathrm{lbs}$. of Cheddar and 11.7 lbs. of Mozzarella, respectively.
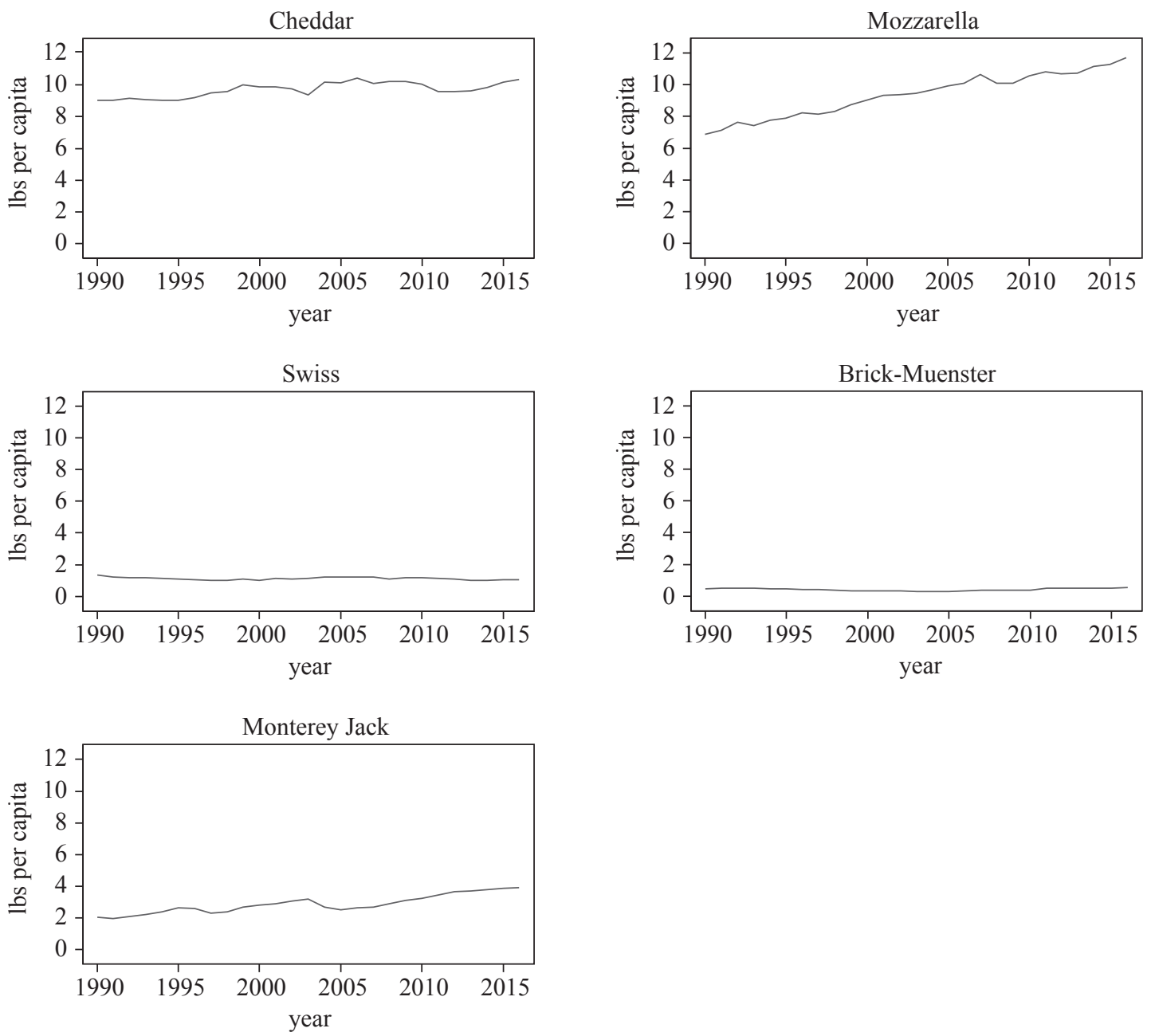

Figure 1. United States cheese consumption per capita.

\footnotetext{
${ }_{1}^{1}$ Per USDA-ERS data available at: https://www.ers.usda.gov/data-products/dairy-data/

${ }^{2}$ Additional cheese varieties of minor consumption within the Other type are: Blue/Gorgonzola, Gouda, Feta, Limburger. There are also additional types of Italian cheese with minor consumption, referred as Other Italian.
} 
Projections and transmission of prices, price discovery process, production and consumption are avenues of investigation; wholesale cheese market behavior and the (dynamic) relationship between retail markets and dairy farms are other veins of research. To our knowledge, there has been no research addressing the dynamic relationship among prices of different cheese varieties, which as noted previously, mainly cater to different consumption settings or markets. How do these prices dynamically evolve, and which price among the different varieties has a leading effect or behaves as reference to the other(s) cheese prices, is a pending matter of investigation. Findings may provide insightful information to a broad spectrum of stakeholders involved in the sector, including investors, price risk managers and policy analysts.

The primary questions are how do these prices dynamically evolve and which of the prices among Cheddar, Mozzarella, Swiss, Brick and Muenster, and Monterey Jack has a leading or reference effect on the other(s) prices. This study intends to fill these gaps in the literature. Findings provide understanding into the price discovery process among these, having risk and management implications, as well as providing information for investment and potential policy (trade) analysis. In effect, agribusiness sectors and chain supply actors involved in cheese markets may benefit from this study's findings, as it identifies dynamic price characteristics and relationships among cheese varieties that may assist in procurement strategies and price risk mitigation. Results may also provide information regarding market characteristics for industry sectors such as dairy (milk) producers or processors analyzing investment perspectives of vertical or horizontal integration, respectively. In addition, policy makers addressing matters of trade, among others, may benefit from these findings.

We proceed by providing a background of the U.S. dairy and cheese industry, followed by describing the data and methodology applied. We then present the results followed by discussion and implications. We conclude with final remarks and future lines of study.

\section{Background}

The dairy industry is the largest agricultural operation for many states in the U.S., including California, Wisconsin, Idaho, New York, Pennsylvania, Michigan, New Mexico, New Hampshire, Utah, and Arizona (USDA-NASS, 2017). Moreover, a large number of these states are the country's top dairy producers, generating billions of dollars in economic activity. In 2014, California's dairy producers and processors alone contributed about 65 billion dollars in sales to their state economy (Sumner et al., 2015). In Wisconsin for 2017, the combination of dairy on-farm and processing contributed 45.6 billion dollars to the state's industrial revenue (Deller, 2019). In 2017, there were about 37,700 dairy farms in the U.S., which accounted for farms with 10 or more milk cows (USDA Census, 2017).

The dairy sector has faced a steady decline in its fluid milk consumption, dropping from $220 \mathrm{lbs}$. per capita in 1990 to 154 lbs. in 2016 (USDA-ERS, 2018). As noted by Jesse and Crop (2004), use of (raw) milk in the U.S. has increasingly shifted to processed dairy products. In 1990, roughly $40 \%$ of all U.S. milk (milk equivalent on butterfat basis) utilization was for fluid milk and cream, whereas in early 2000 this ratio dropped to just a bit lower than $32 \%$ and continues to decline. Conversely, production and consumption of processed dairy products have experienced a continuous growth. Data from 2012 (USDA-NASS, 2013) notes that milk utilization (on a butterfat basis) for cheese and whey production increased to $41 \%$ in 2012 compared to $37 \%$ in 2003. For this same period, fluid milk dropped from $23 \%$ in 2003 to $15 \%$ in 2003 (USDA-NASS, 2004). As for total milk solids (butterfat and nonfat milk solids), utilization in 2012 was highest for cheese and whey production at $37 \%$ followed by $23 \%$ used for fluid milk production; these ratios hold rather similarly for 2018 (USDA-ERS, 2019).

An early study by Kinnucan and Forker (1987) researched the effects from price changes at the farm and retail level, for fluid milk, butter, cheese and ice-cream, and found that all markets experienced some level of price asymmetry adjustment. Awokuse and Wang (2009) studied asymmetric price transmission for fluid milk, butter, and cheese between producers and retailers, and found that fluid milk and butter had asymmetric price adjustments, but not in the case of cheese. Conversely, Stewart and Blayney (2011) studied farm-to- 
retail price transmission for whole milk and cheese, and found evidence of asymmetric adjustments in both markets. A recent study by Hahn et al. (2016) investigated the transmission of dairy prices from farm to retailers by applying a threshold vector error correction model (VECM) that includes soft, gradual changes between different regimes of co-integration. The authors find significant evidence of asymmetric price transmission, though it is economically insignificant to dairy producers.

The U.S. cheese market has been steadily growing since the 1990s, and has become a major player in the dairy sector. The U.S. is consuming twice as much cheese as in 1980 (Durisin, 2017) with per capita annual cheese consumption rising from about $24.6 \mathrm{lbs}$. in 1990 to $37.9 \mathrm{lbs}$. in 2018 (USDA-ERS, 2018) ${ }^{3}$. This burgeoning growth of the U.S. cheese market during the past decades has had domestic cheese production and consumption steadily climbing by 76 and 66\%, respectively from 1995 to 2016 . Cheese production in 2016 was 12.2 billion lbs. and the market consumed 11.8 billion lbs. (USDA-ERS, 2016). Bolotova and Novakovic (2015) investigated the pricing practices used by cheese wholesalers on the Chicago Mercantile Exchange (CME) spot cheese market, finding evidence of oligopolistic behavior. Previously, Arnade et al. (2007) studied the level of retail competition in the U.S. cheese market, finding that the existence of price markups suggested the presence of imperfect competitive behavior

In terms of world cheese supply, in 2017 the U.S. had an output of 13 billion lbs. covering $28.7 \%$ of the global production and only trailed the E.U. - which produced approximately 22.3 billion lbs. encompassing about $49.4 \%$ of global output. The U.S. however produces roughly seven times the cheese of the world's next producers in Russia and Brazil (USDA-FAS, 2018). Gould and Villareal (2002), and more recently Carvalho et al. (2015) and Newton (2016) have studied the effect of international dairy prices on U.S. prices, arriving at mixed results. The former two studies found no effect from international prices; however, the latter study found significant impacts when considering dairy commodity prices instead of all milk prices

\section{Data and methods}

Weekly average Wisconsin wholesale cheese prices for Cheddar, Mozzarella, Swiss, Brick-Muenster, and Monterey Jack from January 2000 to April 2015 are obtained from the USDA Dairy Market News ${ }^{4}$. Descriptive statistics of the data are reported in Table 1. The mean prices for the different cheese varieties fluctuated between $\$ 2.10 / \mathrm{lb}$. to $\$ 2.79 / \mathrm{lb}$. The highest average price was $\$ 2.79 / \mathrm{lb}$. for Swiss, followed by Monterey (\$2.23/lb.), Mozzarella (\$2.21/lb.), Cheddar (\$2.16/lb.) and Brick-Muenster (\$2.10/lb.). Despite Swiss having a larger standard deviation (0.359) and mean (2.785) than Cheddar (0.289 and 2.158, respectively), from the coefficient of variations it can be noted that the larger dispersion or deviations from the mean is for Cheddar (13.396\%) in comparison to Swiss (12.899\%). Moreover, the highest deviations from the mean is for Brick-Muenster (16.964\%), followed by Mozzarella (13.938\%), Cheddar, Swiss and Monterey (11.764\%).

Table 1. Descriptive statistics of data: weekly price January 2000- April 2015 ( $\mathrm{n}=780) .{ }^{1}$

\begin{tabular}{llllllll}
\hline Variables & Unit & Mean & Std. Dev & $\mathbf{C V}^{\mathbf{2}} \mathbf{( \% )}$ & Min. & Max. & Autocorrelation \\
\hline Cheddar & $\$ /$ lbs & 2.158 & 0.289 & 13.396 & 1.744 & 2.993 & 0.989 \\
Mozzarella & $\$ /$ lbs & 2.212 & 0.308 & 13.938 & 1.765 & 3.080 & 0.992 \\
Swiss & $\$ / \mathrm{lbs}$ & 2.785 & 0.359 & 12.899 & 2.243 & 3.769 & 0.994 \\
Brick-Muenster & $\$ / \mathrm{lbs}$ & 2.103 & 0.357 & 16.964 & 1.516 & 3.000 & 0.991 \\
Monterey & $\$ / \mathrm{lbs}$ & 2.234 & 0.263 & 11.764 & 1.847 & 2.977 & 0.988 \\
\hline
\end{tabular}

${ }^{1}$ Prices are nominal (i.e. not deflated); data from USDA Dairy Market News (Data available at: https://www.marketnews.usda. gov/mnp/da-home).

${ }^{2} \mathrm{CV}=$ coefficient of variation.

${ }^{3}$ Does not include cottage cheese. 
Lastly, the high level of autocorrelation for each series is an early indication of the potential presence of non-stationarity. This is formally tested below.

Figure 2 illustrates the evolution of the prices, where it can be noted that Swiss cheese tends to have a certain premium over the other types of cheese. This has been the regular case except for brief periods where demand outpaced supply in comparison to the other cheese varieties, which occurred in April-May of 2004, second half of October of 2012, and less pronounced in late March, 2014.

Unit root tests were conducted to each series by applying the Augmented Dickey-Fuller test (Dickey and Fuller, 1981) and the Kwiatkowski-Phillips-Schmidt-Shin (KPSS) test (Kwiatkowski et al., 1992). Test results indicate non-stationary prices series. We then conducted a co-integration test (Johansen, 1991) to determine the long-run relationships among the cheese prices.
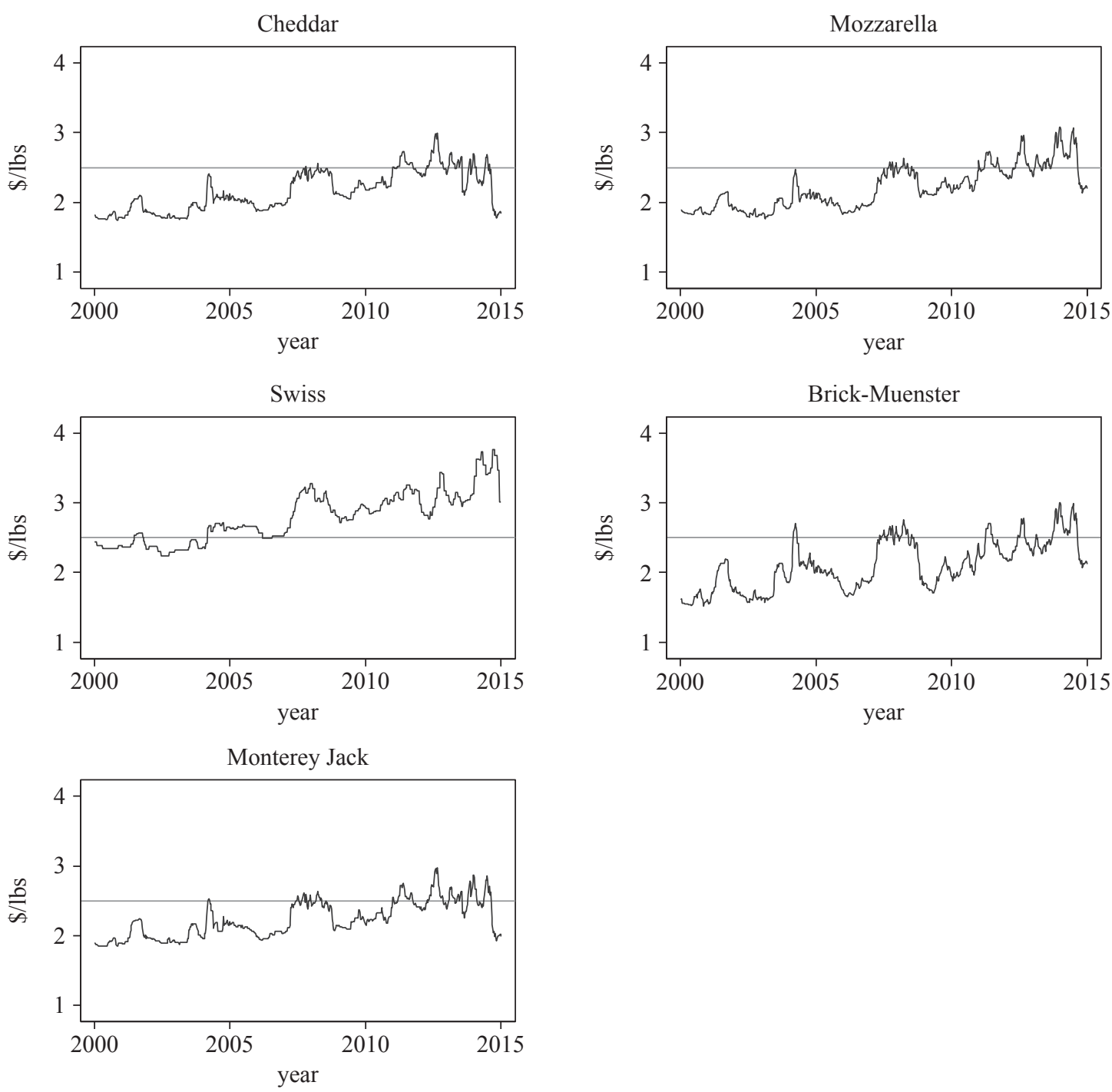

Figure 2. United States cheese weekly prices - January 2000-April $2015(\mathrm{n}=780)$. $\$ 2.50$ grey line serves as reference for comparison of price progress among graphs. 
A structural VECM is estimated in accordance with non-stationary data (Enders, 2004), considering $p$ lags:

$$
\Delta \mathrm{y}_{t}=\Pi \mathrm{y}_{t-1}+\sum_{i=1}^{p-1} \Gamma_{i} \Delta \mathrm{y}_{t-i}+\mathrm{e}_{t} \quad(t=1, \ldots T)
$$

where $\Delta$ is the first difference operator (e.g. $\left.\Delta y_{t}=y_{t}-y_{t-1}\right) ; y_{t}$ is a $(k \times 1)$ vector of prices, $\Pi$ is a $(k \times k)$ coefficient matrix of rank $r$ (number of co-integration vectors, $0<r<k$ ) such that $\Pi=\alpha \beta$, where $\beta$ is a $(k \times r)$ matrix of co-integrating parameters and $\alpha$ is a $(k \times r)$ matrix of 'speed of adjustment' parameters; $\Gamma_{i}$ is a $(k \times k)$ matrix of short-run dynamic coefficients; $e_{t}$ is a $(k \times 1)$ vector of error terms. The optimal lag length of the VECM is one less than the lag length of a level vector autoregression (VAR), and Akaike information criterion (AIC), Schwarz information criterion (SBC) and Hannan-Quinn information criterion (HQIC) criteria are applied to estimate the number of optimal lags of a corresponding level VAR.

After estimating VECM from Equation 1, standard innovation accounting techniques comprising Forecast Error Variance Decomposition (FEVD) and Impulse Response Functions (IRF) (Enders, 2004) are applied. Innovation accounting techniques (FEVD and IRF) enable to draw inferences from dynamic adjustments of each variable(s) - cheese varieties - in response to unexpected shocks from the other variable(s). However, for proper application of innovation accounting, causal directions among the contemporaneous estimated residuals $\left(\hat{e}_{t}\right)$ from (1) have to be assigned, in the regular case that these residuals are correlated. The identification of using restrictions on the long run effects of residuals has become popular (Breitung et al., 2004) given its importance in determining the contemporaneous causal structure - which governs all the subsequent dynamics of the variables in the system. Conventional approaches to addressing these restrictions are the Choleski or the Bernanke factorization decomposition, which uses human judgment and/or economic theory in assigning causal flows among the residuals (Bessler and Palma, 2018; Enders, 2004). For this study we do not have any theory of the cheese markets and make use of the directed acyclic graph (DAG) analysis (Pearl, 2000, 2009). DAG analysis identifies the contemporaneous causal relationship among the residuals based on the causal information contained in the data. This contemporaneous causal structure, the Bernanke factorization, permits calculation of innovations and application of innovation accounting (Bessler et al., 2002; Swanson and Granger, 1997). That is, innovations are assumed to be related to the model residuals according to the relation, $\mathrm{u}_{t}=\mathrm{Be}_{t}$, where $\mathrm{B}$ is $(k \times k)$ matrix. And for the contemporaneous structure of the residuals, estimation of the matrix B is identified by making use of the DAG analysis (Pearl, 2000, 2009).

The residuals are previously tested for normality to verify if Gaussian conditions exist, by applying the Shapiro-Wilk normality test (Shapiro and Wilk, 1965) and results are corroborated with the Jarque-Bera test (Jarque and Bera, 1987). If residuals from our modeled data do not hold Gaussian characteristics, the LiNGAM (Linear Non-Gaussian Acyclic Model) algorithm in TETRAD (Ferndale, WA, USA) developed by Shimizu et al. (2006a) and expanded in Shimizu and Kano (2008), is used to identify the contemporaneous causal patterns through DAG. The LiNGAM algorithm to be applied follows Lai and Bessler (2015). See Supplementary Material for more discussion about the LinGAM algorithm.

The calculated IRFs from standard innovation accounting permit the identification of dynamic adjustments, in terms of direction and magnitude, of each variable (variety) in the system in response to a single unit shock from a variable - while holding the other variables constant. The IRFs are generated by separately shocking the innovations from each of the variables, by one standard deviation. The FEVD analysis from innovation accounting is conducted by decomposing the variance of forecasted errors of each variable, permitting the identification of the relative proportion of movements in a sequence due to its own shocks as well as from shocks to the other variables. When own shocks explain all of the forecast error variance of a specific variety, this variable (variety) may be considered exogenous with respect to the other variables in the system. Conversely, if a large proportion of the FEVD from a variety's price sequence can be explained by shocks to one or more of the other variables, then this variety is considered endogenous to the system. Moreover, the FEVD approach permits to draw inferences with respect to the magnitude and degree of influence on a variety's variance of forecasted errors, from (all) the variables (varieties) in the system. 


\section{Results}

Application of two different unit root tests are conducted and results are reported in Table 2. As shown in Table 2, both tests confirm that all series of cheese prices are non-stationary, and that all first difference series are stationary. After confirming the presence of unit roots, the Johansen's trace test for co-integration (Johansen, 1991) was applied. Based on the trace-test statistics in Table 3, the number of cointegrating vectors was determined to be two. A VECM model is estimated with the optimal lags of the level VAR model determined to be two, leading the optimal lag length for the VECM model to be one.

Normality tests applied to the residuals of the estimated VECM(1) model found that the residuals are generally non-Gaussian (results are not reported to save space, and available upon request). Thus the LiNGAM algorithm with a prune factor of 1.0 is applied, with results shown in Figure 3. From these results, it can be inferred that Mozzarella is the simultaneous price information 'source', transmitting instantly price information to Cheddar, which concurrently transmits the price information to Muenster and Monterrey Jack. Muenster also simultaneously transmits price information to Monterrey Jack. Swiss cheese does not receive or transmit any type of contemporaneous price information.

Table 2. Augmented Dickey-Fuller (ADF) and Kwiatkowski-Phillips-Schmidt-Shin (KPSS) unit root tests considering a trend. ${ }^{1}$

\begin{tabular}{|c|c|c|c|c|c|}
\hline \multirow[t]{2}{*}{ Raw data } & \multicolumn{5}{|c|}{ ADF test (non-zero mean) } \\
\hline & Cheddar & Mozzarella & Swiss & Muenster & Monterey \\
\hline Test statistics & -2.483 & -2.507 & -2.428 & -2.707 & -2.835 \\
\hline $\operatorname{Lags}^{2}$ & 1 & 1 & 5 & 1 & 1 \\
\hline $1 \%$ critical value & -3.43 & -3.43 & -3.43 & -3.43 & -3.43 \\
\hline \multirow[t]{3}{*}{ Decision } & NS & NS & NS & NS & NS \\
\hline & \multicolumn{5}{|c|}{ KPSS test (level stationarity) } \\
\hline & Cheddar & Mozzarella & Swiss & Muenster & Monterey \\
\hline$Z(t)$ stat & 7.149 & 7.940 & 8.771 & 5.574 & 6.605 \\
\hline $\operatorname{Lags}^{2}$ & 6 & 6 & 6 & 6 & 6 \\
\hline $1 \%$ critical value & 0.739 & 0.739 & 0.739 & 0.739 & 0.739 \\
\hline Decision & NS & NS & NS & NS & NS \\
\hline \multirow[t]{2}{*}{ First difference } & \multicolumn{5}{|c|}{ ADF test (non-zero mean) } \\
\hline & $\Delta$ Cheddar & $\Delta$ Mozzarella & $\Delta$ Swiss & $\Delta$ Muenster & $\Delta$ Monterey \\
\hline Test statistics & -23.256 & -21.232 & -8.759 & -20.409 & -22.138 \\
\hline $\operatorname{Lags}^{2}$ & 0 & 0 & 4 & 0 & 0 \\
\hline $1 \%$ critical value & -3.43 & -3.43 & -3.43 & -3.43 & -3.43 \\
\hline \multirow[t]{3}{*}{ Decision } & $\mathrm{S}$ & $\mathrm{S}$ & $\mathrm{S}$ & $\mathrm{S}$ & $\mathrm{S}$ \\
\hline & \multicolumn{5}{|c|}{ KPSS test (level stationarity) } \\
\hline & $\Delta$ Cheddar & $\Delta$ Mozzarella & $\Delta$ Swiss & $\Delta$ Muenster & $\Delta$ Monterey \\
\hline$Z(t)$ stat & 0.094 & 0.045 & 0.035 & 0.041 & 0.069 \\
\hline $\operatorname{Lags}^{2}$ & 6 & 6 & 6 & 6 & 6 \\
\hline $1 \%$ critical value & 0.739 & 0.739 & 0.739 & 0.739 & 0.739 \\
\hline Decision & $\mathrm{S}$ & $\mathrm{S}$ & $\mathrm{S}$ & $\mathrm{S}$ & $\mathrm{S}$ \\
\hline
\end{tabular}

${ }^{1} \mathrm{ADF}$ test - testing the null hypothesis of non-stationarity, thus the series is stationary by rejecting null hypothesis, KPSS test - testing the null hypothesis of stationarity, thus the series is stationary by failing to reject null hypothesis; NS = nonstationary; $\mathrm{S}=$ stationary. ${ }^{2}$ Lags for ADF test is determined by minimizing Schwarz criterion and for KPSS test is given by Newey-West lags, int $\left\{4(T / 100)^{2 / 9}\right\}$, where $T$ is the number of observations. 
Table 3. Trace test on order of co-integration.

\begin{tabular}{|c|c|c|c|c|c|c|}
\hline Rank & Trace $^{* 1}$ & $C * 1$ & Decision $^{3}$ & Trace $^{2}$ & $\mathrm{C}^{2}$ & Decision $^{3}$ \\
\hline$r=0$ & 133.91 & 76.81 & reject & 144.20 & 88.55 & reject \\
\hline $\mathrm{r} \leq 1$ & 71.19 & 53.94 & reject & 79.95 & 63.66 & reject \\
\hline $\mathrm{r} \leq 2$ & 25.27 & 35.07 & fail to reject & 33.80 & 42.77 & fail to reject \\
\hline$r \leq 3$ & 10.18 & 20.16 & fail to reject & 18.07 & 25.73 & fail to reject \\
\hline $\mathrm{r} \leq 4$ & 0.47 & 9.14 & fail to reject & 6.20 & 12.45 & fail to reject \\
\hline
\end{tabular}

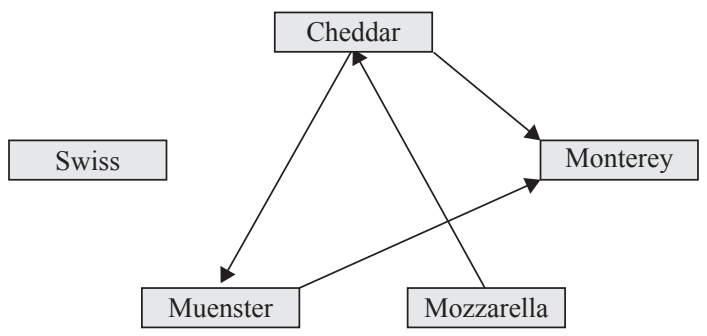

Figure 3. Non-time causality directions of cheese markets - prune factor: 1.0.

The FEVD are studied for each market considering a period of up to 24 weeks. Table 4 shows the decomposition of forecast error variances for the five cheese varieties. In the case of Cheddar, the variance of forecast errors of its prices is mainly explained by shocks to its own price (Cheddar price). It also experiences a small effect from shocks to Mozzarella prices especially for the first two weeks, and then this effect decreases remaining minor through the following weeks. In addition, there is a very small effect from shocks to the price of Muenster during the second and third weeks, but this effect subsequently remains quite small as well.

The variance of forecasted errors for the Mozzarella variety is also largely due to shocks to its own prices, more so than in the case of Cheddar cheese. Moreover, Mozzarella's FEVD are lightly impacted by changes in Muenster prices in a similar manner to the effects Muenster had on Cheddar. The Swiss cheese variety is the sole responsible of variation of forecasted errors during its first week. By the $12^{\text {th }}$ week and beyond, its variations of forecasted errors are increasingly responding to shocks to Mozzarella prices and a bit less responsive from shocks to Muenster. From the initial weeks, the Muenster variety has about half of the variability in its forecasted errors of prices responding to unanticipated price changes in Cheddar, as well as from its own. That is, unexpected changes in Cheddar prices play a substantial role (roughly about $45 \%$ ) in the variability of forecasted errors of Muenster prices.

Lastly, variations in the forecasted errors of Monterey prices respond in a majority (about $75 \%$ ) to shocks from Cheddar prices, as well as rising effects from Muenster's unexpected price variability - which grows from eight to $19 \%$. In addition, Monterrey is the only cheese variety where variation of its forecasted errors of prices depends very little on its own shocks, and it decreases even more as time passes.

From IRFs shown in Figure 4 we observe in the first column that one-time shocks to the Cheddar price significantly impacts Muenster and Monterrey prices in a positive lasting manner. Conversely, in the second column, a one-time shock to Mozzarella price has an immediate positive and significant effect on Cheddar that lasts until the third week, after which it fades becoming insignificant. A one-time Mozzarella price shock also has a positive and permanent effect on the Swiss prices, significant from the eighth week onward. The Swiss price's one-time shock, in the third column, produces non-significant results in all other cheese varieties' prices, thus not having any effect on them. A one-time shock to the Muenster price, in the fourth 
Table 4. Forecast error variance decompositions. ${ }^{1}$

\begin{tabular}{|c|c|c|c|c|c|c|}
\hline \multirow[b]{2}{*}{ Weeks } & \multirow{2}{*}{$\begin{array}{l}\text { Variation } \\
\text { in } \downarrow\end{array}$} & \multicolumn{2}{|c|}{ Accounted for by $\rightarrow$} & \multirow[b]{2}{*}{ swis } & \multirow[b]{2}{*}{ muen } & \multirow[b]{2}{*}{ mont } \\
\hline & & ched & mozz & & & \\
\hline 1 & ched & 0.91 & 0.09 & 0.00 & 0.00 & 0.00 \\
\hline 2 & & 0.91 & 0.06 & 0.01 & 0.02 & 0.00 \\
\hline 3 & & 0.90 & 0.05 & 0.01 & 0.04 & 0.00 \\
\hline 4 & & 0.89 & 0.05 & 0.01 & 0.04 & 0.00 \\
\hline 8 & & 0.89 & 0.05 & 0.01 & 0.05 & 0.00 \\
\hline 12 & & 0.89 & 0.05 & 0.01 & 0.05 & 0.00 \\
\hline 16 & & 0.90 & 0.04 & 0.00 & 0.05 & 0.00 \\
\hline 20 & & 0.91 & 0.04 & 0.00 & 0.05 & 0.00 \\
\hline 24 & & 0.91 & 0.04 & 0.00 & 0.05 & 0.00 \\
\hline 1 & mozz & 0.00 & 1.00 & 0.00 & 0.00 & 0.00 \\
\hline 2 & & 0.01 & 0.96 & 0.01 & 0.02 & 0.00 \\
\hline 3 & & 0.02 & 0.94 & 0.01 & 0.03 & 0.00 \\
\hline 4 & & 0.02 & 0.93 & 0.01 & 0.04 & 0.00 \\
\hline 8 & & 0.02 & 0.92 & 0.01 & 0.05 & 0.00 \\
\hline 12 & & 0.02 & 0.92 & 0.01 & 0.05 & 0.00 \\
\hline 16 & & 0.02 & 0.92 & 0.01 & 0.05 & 0.00 \\
\hline 20 & & 0.02 & 0.92 & 0.01 & 0.05 & 0.00 \\
\hline 24 & & 0.02 & 0.91 & 0.01 & 0.05 & 0.00 \\
\hline 1 & swis & 0.00 & 0.00 & 1.00 & 0.00 & 0.00 \\
\hline 2 & & 0.00 & 0.00 & 0.99 & 0.00 & 0.00 \\
\hline 3 & & 0.00 & 0.00 & 0.99 & 0.01 & 0.00 \\
\hline 4 & & 0.00 & 0.00 & 0.99 & 0.01 & 0.00 \\
\hline 8 & & 0.00 & 0.03 & 0.94 & 0.02 & 0.00 \\
\hline 12 & & 0.00 & 0.08 & 0.87 & 0.04 & 0.01 \\
\hline 16 & & 0.00 & 0.14 & 0.78 & 0.06 & 0.01 \\
\hline 20 & & 0.01 & 0.21 & 0.69 & 0.07 & 0.01 \\
\hline 24 & & 0.01 & 0.28 & 0.61 & 0.08 & 0.01 \\
\hline 1 & muen & 0.48 & 0.00 & 0.00 & 0.52 & 0.00 \\
\hline 2 & & 0.44 & 0.00 & 0.00 & 0.56 & 0.00 \\
\hline 3 & & 0.42 & 0.00 & 0.01 & 0.58 & 0.00 \\
\hline 4 & & 0.41 & 0.00 & 0.01 & 0.58 & 0.00 \\
\hline 8 & & 0.39 & 0.00 & 0.01 & 0.60 & 0.00 \\
\hline 12 & & 0.39 & 0.00 & 0.00 & 0.60 & 0.00 \\
\hline 16 & & 0.39 & 0.00 & 0.00 & 0.61 & 0.00 \\
\hline 20 & & 0.39 & 0.00 & 0.00 & 0.61 & 0.00 \\
\hline 24 & & 0.39 & 0.00 & 0.00 & 0.61 & 0.00 \\
\hline 1 & mont & 0.78 & 0.00 & 0.00 & 0.08 & 0.14 \\
\hline 2 & & 0.75 & 0.00 & 0.00 & 0.13 & 0.11 \\
\hline 3 & & 0.73 & 0.01 & 0.01 & 0.16 & 0.09 \\
\hline 4 & & 0.73 & 0.01 & 0.01 & 0.17 & 0.08 \\
\hline 8 & & 0.72 & 0.02 & 0.01 & 0.19 & 0.06 \\
\hline 12 & & 0.72 & 0.03 & 0.01 & 0.19 & 0.04 \\
\hline 16 & & 0.72 & 0.04 & 0.01 & 0.19 & 0.03 \\
\hline 20 & & 0.73 & 0.04 & 0.01 & 0.19 & 0.03 \\
\hline 24 & & 0.73 & 0.04 & 0.01 & 0.19 & 0.03 \\
\hline
\end{tabular}

1 ched $=$ Cheddar mozz $=$ Mozzarella, swis $=$ Swiss, muen $=$ Muenster, and mont $=$ Monterey . 

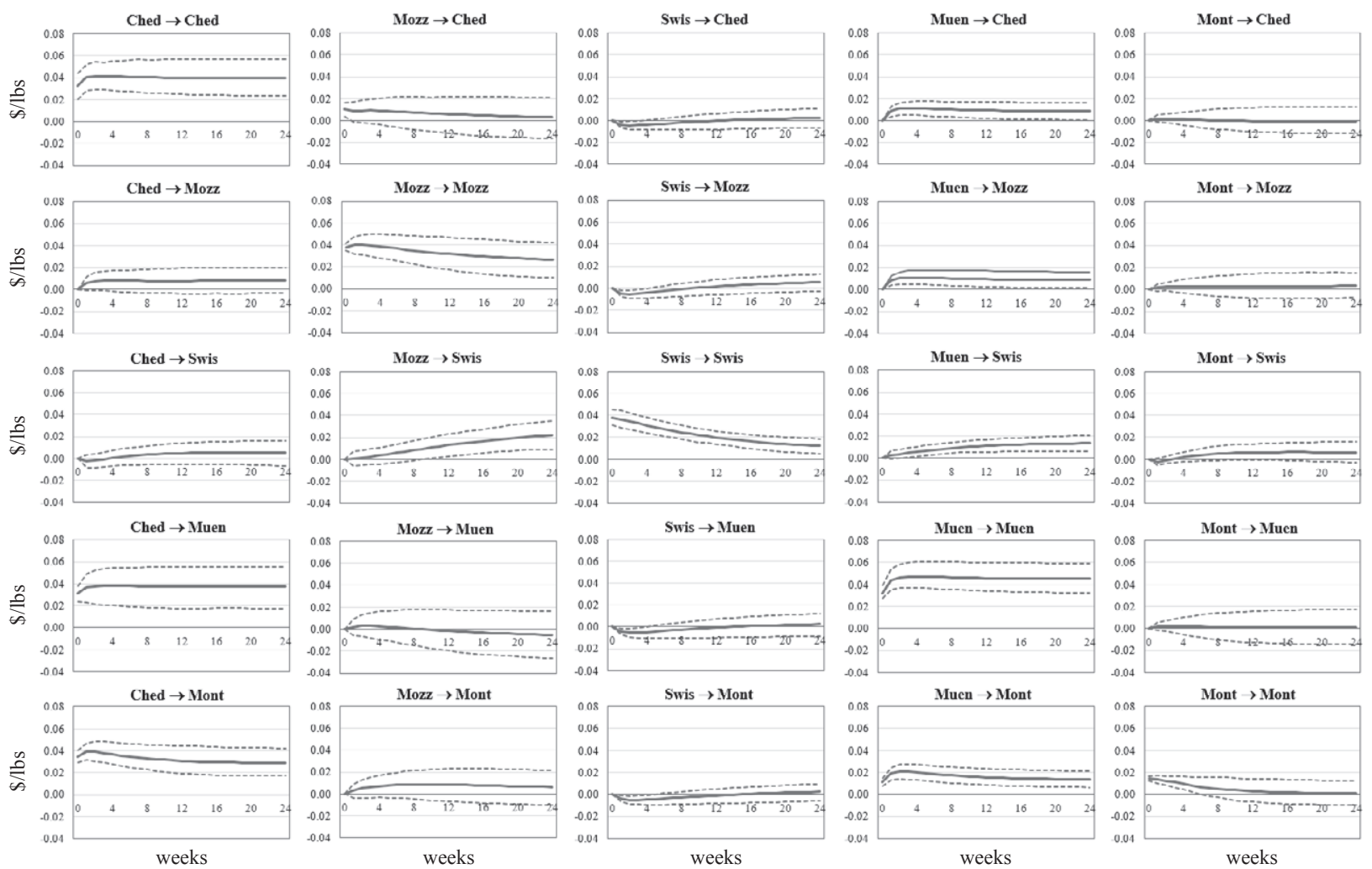

Figure 4. Impulse response functions. Ched $=$ Cheddar; Mozz = Mozzarella; Swis $=$ Swiss; Muen = Muenster; Mont $=$ Monterey; continuous line $=$ result of the impulse response functions; dotted lines $=95 \%$ Hall percentile confidence band with 1000 bootstrapping (Hall, 1992).

column, produces a brief significant positive effect for about four weeks on the Mozzarella and Cheddar prices. In addition, a one-time Muenster price shock produces a permanent and positive significant effect on the Swiss and Monterey prices. Lastly, a one-time shock to Monterey prices does not produce a significant effect on any of the other varieties, in similar manner to the one-time shock on Swiss prices.

Results suggest that Cheddar, Monterey and Muenster prices move somewhat together, and the latter and may be influenced by the first two cheese varieties from the American types of cheese. Results also seem to indicate that Cheddar is a leading, reference price among these three cheese varieties. The Mozzarella and Swiss cheese prices seem to be decoupled or separated. Mozzarella is an Italian type of cheese, which has gained steady growth in consumption serving as a base ingredient to the pizza industry - a staple in the fast-food industry. Mozzarella also serves in minor form as a reference price for the Swiss prices. Swiss cheese generally commands a premium price over the other varieties' prices, and is only slightly affected by price variations from Mozzarella. Moreover, Swiss price changes do not have an effect on any of the other cheese varieties.

\section{Conclusions and implications}

The U.S. cheese sector has substantially expanded and been steadily growing throughout the years. Since 1980, U.S. consumers have doubled their annual consumption of cheese, currently at about $36.6 \mathrm{lbs}$. per capita in 2016 excluding cheese in processed food. Generally, cheese varieties are classified as American type (Cheddar, Monterey and others), Italian type (Mozzarella and others), and Other type (Swiss, Muenster and others). This study investigates the dynamic price relationships and price discovery process among cheese varieties of different types: Cheddar, Mozzarella, Swiss, Muenster, and Monterey by using a VECM to Wisconsin wholesale price data from January 2000 and April 2015 (weekly total of 780 observations), 
and applying standard innovation accountings. After confirming the presence of unit roots, the Johansen's trace test suggests that there exist two long-run relationships.

Results from this study reveal that wholesale prices of these U.S. cheese varieties seem to be decoupled or separated as: (1) Cheddar, Muenster and Monterey with Cheddar being the leading or reference price among these three varieties; (2) Mozzarella; and (3) Swiss, with Mozzarella being a minor reference price for the Swiss market though not vice-versa. These findings may respond to different cheese types being (mostly) utilized and consumed in different forms. The first group of cheeses tend to be consumed primarily as an additional ingredient of sandwiches, burgers, and/or with other similar types of food (wraps, etc.) and thus may potentially serve as substitutes to each other. Mozzarella is dominantly used in pizza production, or served with pastas and other Italian cuisine, while Swiss cheese is usually consumed directly.

These results provide insightful findings for agribusiness sectors and chain supply actors involved in cheese markets, as it identifies dynamic price characteristics and relationships among cheese varieties that may assist in procurement strategies and risk mitigation. Results also provide information regarding market characteristics for industry sectors such as dairy (milk) producers or processors analyzing investment perspectives of vertical or horizontal integration, respectively. In addition, policy makers addressing matters of trade involving these cheese varieties may benefit from these findings.

Future lines of study include investigating the dynamic relationship of CME futures spot cheese prices on these prices, taking into account that CME trades encompass less than $1 \%$ of all U.S. cheese production.

\section{Supplementary material}

Supplementary material can be found online at https://doi.org/10.22434/IFAMR2019.0206

Appendix 1. LinGAM algorithm.

\section{References}

Arnade, C., M. Gopinath and D. Pick. 2007. Measuring the degree of retail competition in U.S. cheese markets. Journal of Agricultural and Food Industrial Organization 5(1): 1-18.

Awokuse, T. and X. Wang. 2009. Threshold effects and asymmetric price adjustments in U.S. dairy markets. Canadian Journal of Agricultural Economics 57(2): 269-286.

Bessler, D.A. and M.A. Palma. 2018. On the evolution of agricultural econometrics. In: Cramer, G.L., K.P. Paudel and A. Schmitz (eds.) The Routledge handbook of agricultural economics. Routledge, London, UK, pp. 467-487.

Bessler, D.A., J. Yang and M. Wongcharupan. 2002. Price dynamics in the international wheat market: modeling with error correction and directed acyclic graphs. Journal of Regional Science 42: 793-825.

Bolotova, Y.V. and A.M. Novakovic. 2015. An empirical analysis of wholesale cheese pricing practices on the Chicago Mercantile Exchange (CME) spot cheese market. International Food and Agribusiness Management Review 18(3): 49-66.

Breitung, J., R. Brüggermann and H. Lütkepohl. 2004. Structural vector autoregressive modeling and impulse responses. In: H. Lutkepohl and M. Kratzig (eds.) Applied time series econometrics. Cambridge University Press, Cambridge, UK, pp. 159-196.

Carvalho, G.R., D. Bessler, T. Hemme and E. Schroer-Merker. 2015. Understanding internal milk price relationships. Selected paper prepared for presentation at the Southern Agricultural Economics Association's Annual Meeting. January 31- February 3, 2015. Atlanta, GE, USA.

Deller, S.C. 2019. The contribution of agriculture to the Wisconsin economy: an update for 2017. Department of Agricultural and Applied Economics, Center for Community Economic Development, University of Wisconsin-Madison, Madison, WI, USA. 
Dickey, D.A. and W.A. Fuller. 1981. The likelihood ratio statistics for autoregressive time series with a unit root. Econometrica 49: 1057-1072.

Durisin, M. 2017. Americans are drinking less milk, but they can't get enough cheese. Bloomberg, January 11. Available at: www.bloomberg.com/news/articles/2017-01-11/cheesier-pizzas-rescue-dairy-pricesas-americans-drink-less-milk

Enders, W. 2004. Applied econometric time series. John Wiley Sons, Inc., New York, NY, USA.

Gould, B.W. and H.J. Villarreal. 2002. A descriptive analysis of recent trends in the international market for dry milk products. Babcock Institute for International Dairy Research and Development, University of Wisconsin, Madison, WI, USA.

Hahn, W., H. Stewart, D.P. Blaney and C.G. Davis. 2016. Modeling price transmission between farm and retail prices: a soft switches approach. Agricultural Economics 47(2): 193-203.

Hall, P. 1992. The bootstrap and Edgeworth expansion. Springer, New York, NY, USA.

Jarque, C.M. and A.K. Bera. 1987. A test for normality of observations and regression residuals. International Statistical Review 55(2): 163-172.

Jesse, E. and B. Cropp. 2004. Basic milk pricing concepts for dairy farmers. Publication no. 3379, University of Wisconsin, Division of Extension, Madison, WI, USA.

Johansen, S. 1991. Estimation and hypothesis testing of cointegration vectors in Gaussia vector autoregressive models. Econometrica 59: 1551-1580.

Kinnucan, H.W. and O.D. Forker. 1987. Asymmetry in farm-retail price transmission for major dairy products. American Journal of Agricultural Economics 69: 285-292.

Kwiatkowski, D., P.C.B. Phillips, P. Schmidt and Y. Shin. 1992. Testing the null hypothesis of stationarity against the alternative of a unit root. Journal of Econometrics 54(1-3): 159-178.

Lai, P. and D.A. Bessler. 2015. Price discovery between carbonated soft drink manufactures and retailers: a disaggregate analysis with PC and LiNGAM algorithms. Journal of Applied Economics18(1): 173-198.

Newton, J. 2016. Price transmission in global dairy markets. International Food and Agribusiness Management Review 19(B): 57-72.

Pearl, J. 2000. Causality. Cambridge University Press, Cambridge, UK.

Pearl, J. 2009. Causality: models, reasoning, and inference, $2^{\text {nd }}$ edition. Cambridge University Press, New York, NY, USA.

Shapiro, S.S. and M.B. Wilk. 1965. An analysis of variance test for normality (complete samples). Biometrika 52(3-4): 591-611.

Shimizu, S. and Y. Kano. 2008. Use of non-normality in structural equation modeling: application to direction of causation. Journal of Statistical Planning and Inference 138: 3483-3491.

Shimizu, S., A. Hyvärinen, P.O. Hoyer and Y. Kano. 2006b. Finding a causal ordering via independent component analysis. Computational Statistics and Data Analysis 50: 3278-3293.

Shimizu, S., P.O. Hoyer, A. Hyvärinen and A. Kerminen. 2006a. A linear non-Gaussian acyclic model for causal discovery. Journal of Machine Learning Research 7: 2003-2030.

Stewart, H. and D.P. Blayney. 2011. Retail dairy prices fluctuate with the farm value of milk. Agricultural and Resource Economics Review 40: 201-217.

Sumner, D.A., J. Medellin-Azuera and E. Coughlin. 2015. Contributions of the California dairy industry to the California economy. Agricultural Issues Center, University of California, Davis, CA, USA.

Swanson, N.R. and C.W.J. Granger. 1997. Impulse response functions based on a causal approach to residual orthogonalization in vector autoregressions. Journal of the American Statistical Association 92: 357-367.

U.S. Department of Agriculture / Economic Research Service (USDA-ERS). 2016. Data files: U.S. and state-level farm income and wealth statistics. USDA-ERS, Washington, DC, USA. Available at: https://www.ers.usda.gov/data-products/farm-income-and-wealth-statistics/data-files-us-and-statelevel-farm-income-and-wealth-statistics/

U.S. Department of Agriculture / Economic Research Service (USDA-ERS). 2017. Per capita consumption of selected cheese varieties (annual). USDA-ERS, Washington, DC, USA. Available at: https://www. ers.usda.gov/data-products/dairy-data/ 
U.S. Department of Agriculture / Economic Research Service (USDA-ERS). 2018. Per capita consumption of selected cheese varieties (annual). USDA-ERS, Washington, DC, USA. Available at: https://www. ers.usda.gov/data-products/dairy-data/

U.S. Department of Agriculture / Economic Research Service (USDA-ERS). 2019. Per capita consumption of selected cheese varieties (annual). USDA-ERS, Washington, DC, USA. Available at: https://www. ers.usda.gov/data-products/dairy-data/

U.S. Department of Agriculture / Economic Research Service (USDA-FAS). 2018. Market and trade dataPSD online. USDA-FAS, Washington, DC, USA. Available at: https://apps.fas.usda.gov/psdonline/ app/index.html\#/app/home

U.S. Department of Agriculture / National Agriculture Statistics Services (USDA-NASS). 2017. Census of agriculture. USDA-NASS, Washington, DC, USA. Available at: https://www.nass.usda.gov/ Publications/AgCensus/2017/index.php

U.S. Department of Agriculture / National Agriculture Statistics Services (USDA-NASS). 2004. Dairy products annual summary, 2004. USDA-NASS, Washington, DC, USA. Available at: https://usda. library.cornell.edu/concern/publications/jm214p131

U.S. Department of Agriculture / National Agriculture Statistics Services (USDA-NASS). 2013. Dairy products annual summary, 2013. USDA-NASS, Washington, DC, USA. Available at: https://usda. library.cornell.edu/concern/publications/jm214p131 
